\begin{tabular}{|l|l|l||}
\hline \multicolumn{2}{|c|}{ PublisherInfo } \\
\hline \hline PublisherName & $:$ & BioMed Central \\
\hline \hline PublisherLocation & $:$ & London \\
\hline \hline PublisherImprintName & $:$ & BioMed Central \\
\hline \hline
\end{tabular}

\title{
NIV for weaning
}

\begin{tabular}{|l|l|l||}
\hline \multicolumn{2}{|c||}{ ArticleInfo } \\
\hline \hline ArticleID & $:$ & 4104 \\
\hline \hline ArticleDOI & $:$ & $10.1186 /$ ccf-1999-2201 \\
\hline \hline ArticleCitationID & $:$ & 2201 \\
\hline \hline ArticleSequenceNumber & $:$ & 41 \\
\hline \hline ArticleCategory & $:$ & Paper Report \\
\hline \hline ArticleFirstPage & $:$ & 1 \\
\hline \hline ArticleLastPage & $:$ & 3 \\
\hline \hline & & RegistrationDate : 1999-11-3 \\
\hline ArticleHistory & $:$ & OnlineDate \\
\hline \hline ArticleCopyright & $:$ & Current Science Ltd1999-11-3 \\
\hline \hline ArticleGrants & $:$ & \\
\hline \hline ArticleContext & $:$ & 130541111 \\
\hline \hline
\end{tabular}




\section{Keywords}

mechanical ventilation, noninvasive ventilation, weaning

\section{Comments}

This was a very well designed and executed trial. Though the eventual sample sizes were small, they appear to have been well matched and represent the real world compromise faced by investigators in this area. The study outcome measures were well set, revealing that although weaning with NIV takes longer, this is at the benefit of a reduction in both 'days intubated' and 'time per day requiring ventilatory support'. In essence, this offers yet more evidence that NIV should be considered a preferable alternative to intubation and mechanical ventilation in many circumstances.

\section{Introduction}

Noninvasive ventilation (NIV) has been proven to be an effective alternative to intubation and mechanical ventilation in the treatment of acute respiratory failure. NIV offers the advantage of preserving the barrier defences of the upper airway and has been shown to reduce the incidence of nosocomial pneumonia, as compared to endotracheal mechanical ventilation (ETMV), with an associated reduction in morbidity and mortality.

\section{Aims}

To evaluate the outcome of weaning patients using NIV versus endotracheal pressure support ventilation (EPSV).

\section{Methods}


Patients with acute-on-chronic respiratory failure, who had required intubation and ventilation, were assessed daily for weaning criteria. If these were met, a $2 \mathrm{~h}$ T-piece weaning trial was conducted. Those who failed this trial were randomized to either EPSV, or extubation and NIV. A strict protocol for weaning from this extended respiratory support was followed.

\section{Results}

Thirty-three patients were recruited over 16 months; 16 were randomized to EPSV and 17 to NIV. Characteristics at admission and at randomization were similar in the two groups. Successful weaning was achieved in 75\% (EPSV group) and 76.5\% (NIV group) of patients. The NIV group required more days of ventilatory support, but less support per day. Complication rates were higher in the EPSV group, but this was not statistically significant. Length of intensive care unit (ICU) and hospital stay, in-hospital and 3 month mortality were similar in the two groups. Oddly, none of the 16 EPSV patients but 7 of the 17 NIV patients required domiciliary NIV at discharge.

\section{Discussion}

This study confirms that NIV offers a viable alternative to EPSV in weaning acute-on-chronic respiratory failure patients who present weaning difficulties. The failure rate was identical and there was a trend towards a reduction in complications. This did not reach significance due to the small sample sizes. The authors argue that reducing the time a patient is intubated, especially a patient with chronic underlying lung disease is very likely to be of significant benefit. They also comment that their success and duration of EPSV was better than those reported by other authors. They claim that this supports the use of a strict protocolized weaning process. They are unable to explain the dramatic difference in the need for domiciliary NIV between the two groups, and speculate that the NIV group had more severe chronic respiratory failure. They conclude that NIV should be considered as a weaning modality in all patients who present weaning difficulties.

\section{References}

1. Girault C, Daudenthun I, Chevron V, Tamion F, Leroy J, Bonmarchand G: Noninvasive ventilation as a systematic extubation and weaning technique in acute-on-chronic respiratory failure. A prospective, randomized controlled study. Am J Respir Crit Care Med. 1999, 160: 86-92.

This PDF file was created after publication. 